\title{
Combined Approach to Treat Medication-Related Osteonecrosis of the Jaws
}

\author{
Elisabetta Merigo ${ }^{1,2}$, Luigi Cella ${ }^{2}$, Aldo Oppici ${ }^{2}$, Maria Cristina Arbasi ${ }^{3}$, Fabio Clini' ${ }^{2}$, Matteo Fontana ${ }^{2}$, Carlo \\ Fornaini ${ }^{1,2^{*}}$
}

'MICORALIS Laboratory EA7354, Faculty of Dentistry, Université "Côte d'Azur", 24 Avenue des Diables Bleus, 06357 Nice, France

${ }^{2}$ Odontostomatology and Maxillo-Facial Surgery Unit - "Special care dentistry", "Guglielmo da Saliceto" Hospital - Via Taverna, 10 - 29100, Piacenza, Italy

${ }^{3}$ Immunohematology and Transfusion Medicine "Guglielmo da Saliceto" Hospital - via Taverna, 10 - 29100, Piacenza, Italy

\section{*Correspondence to Carlo Fornaini, MICORALIS Laboratory EA7354 Faculty of Dentistry, Université "Côte d'Azur", 24 Avenue des Diables Bleus, 06357 Nice, France. \\ Tel: +33492001111 Fax +33492001263 Email: carlo@fornainident.it}

Published online 20 March 2018

\begin{abstract}
Introduction: The proper therapeutic plan for medication-related osteonecrosis of the Jaw (MRONJ) is still lacking long-term data up to today. They were several high-technological appliances proposed for the different intervention steps, in addition to tissue repair promoters. The reason for proposing an integrated technique is justified, beyond better compliance of the patients associated to the pain and inflammation reduction and bleeding control, there is also achieving better hard and soft tissues healing.

Methods: Patients diagnosed with bisphosphonates-related osteonecrosis of the jaws (BRONJ) at the Odontostomatology and Maxillo-Facial Surgery Unit of the Hospital of Piacenza undergone surgical intervention. The intervention was performed by using different devices: Piezosurgery for removing the necrotic bone tissue and for obtaining the bone specimen essential for histological analysis; Er:YAG laser $(2940 \mathrm{~nm})$ to vaporize necrotic hard tissue until reaching the bleeding bone; platelet-rich plasma (PRP) to stimulate hard and soft tissue healing; and finally diode laser (808 $\mathrm{nm}$ ) to perform a biostimulation of the surgical site.

Results: All treated patients demonstrated a good postoperative comfort even without using painkillers, no bleeding, and a fast healing process. Most of the patients $(92.85 \%)$ reached complete healing with a minimum follow up at 6 months. Histological exams demonstrated a good quality without artifacts.

Conclusion: Sequential utilization of different high-technologies devices during all the steps of MRONJ treatment allows to perform a faster and less invasive surgery with a more comfortable postoperative healing process and it may represent a new and original approach for treating this severe adverse event.
\end{abstract}

Keywords: Medication-related osteonecrosis of the jaws; BRONJ; Laser; Piezosurgery; Platelet-rich factor.

\section{Introduction}

Recently, the "American Association of Oral and Maxillofacial Surgeons" (AAOMS) proposed to change the term "bisphosphonates-related osteonecrosis of the jaws" (BRONJ) into "medication-related osteonecrosis of the jaws" (MRONJ) based on the growing number of its clinical cases involving the maxilla and mandible associated with other anti-resorption (denosumab) and anti-angiogenic drugs. ${ }^{1}$ The diagnosis for MRONJ, based also on radiological and serological (CTX) data, does not yet give a clear indication for the treatment protocol. ${ }^{2-4}$ A recent review of the literature has well exposed that the scientific community has not found a viable solution to counter this challenging disease, ${ }^{5}$ and the emphasis that has been placed by the AAOMS on the preventive aspects for this disease, unmasks the current uncertainty regarding the therapeutic approach.

Although there is no consensus on a resolving therapy for this disease, surgery plays a key role: the results for the surgical approach appear to be better than that of the conservative one. ${ }^{6}$

These drugs create some alteration in bone homeostasis by the alteration of the bone turnover balance and the angiogenic pathway.

This disease implications are particularly insidious for several reasons:

(a) The mechanism by which it achieves bone necrosis is not clear, it is often (about $60 \%$ of cases) apparently 
spontaneous, while in the rest of the cases it is related to dental procedures and so not classified as an acute event ${ }^{7}$; (b) These drugs, particularly bisphosphonates (BFs), may remain bioavailable for several years, their action persisting a long time after therapy and/or recurring even years after the treatment ${ }^{8}$;

(c) Drugs holiday does not significantly improve the state of necrosis even if this strategy is considered as a prudent approach by different scientific societies;

(d) The presence of compromised teeth, as well as the surgical act of their removal, can trigger the disease;

(e) Otherwise, it is different from osteoradionecrosis, where bleeding bone is the sign of viable bone, in MRONJ this is not guaranteed of healthy tissue; this has led several authors to recommend a conservative approach in treating $\mathrm{MRONJ}^{10}$;

(f) The imbalance of bone cell turnover in osteoblastic activity seems to be an imbalance of the whole bone extracellular matrix, although there is no consensus on this ${ }^{11}$;

(g) Although the histology of the intraoral soft tissues appears normal, ${ }^{12}$ these drugs also create some changes in the epithelium, so determining a deterioration of its quality. ${ }^{13-15}$

If the disease is diagnosed in the early stage and systemic conditions are good, the curettage may be successful; in advanced cases with severe systemic disease, a more invasive approach with the use of free micro-vascularized flap with fibula or iliac crest may be necessary. ${ }^{16}$

In the past years, bone marrow stem cells (BMSCs) have been proposed to promote healing of osteonecrotic sites, ${ }^{17}$ due to their ability to differentiate into different human tissues, revealing a promising therapeutic option in different fields of application.

The BMSC are multipotent stem cells (MSCs) able to differentiate into different human tissues and bone marrow represents a rich bank. ${ }^{18,19}$

The BMSC belong to the category of MSCs which, together with those of adipocytes and umbilical cord, may differentiate into different mature tissues (bone marrow, cartilage, adipose tissue, muscle, nerve).

MSCs are found widely in the human body, especially in organs with high cell turnover (skin, epithelium) and they reside in niches that are 3-D micro-environments where they participate in tissue homeostasis.

The mechanism by which stem cells (MSC) localize themselves is still not well defined.

Very few MSC were found circulating in the peripheral blood, and when injected, they have little capacity to localize themselves in normal conditions.

The difference of results between orthopedics and maxillofacial surgery use of BMSC is linked to the different quality of the surrounding tissues.

Literature proposed, as an adjuvant therapy for different bone diseases, platelet-rich plasma (PRP) which is largely used in maxillofacial surgery ${ }^{20-22}$ and in many other medical fields. The rationale for its use is the addition of growth factors (GFs) in suffering environments. PRP, in fact, contains many GFs such as fibroblast growth factor (FGF), epidermal growth factor (EGF), keratinocyte growth factor (KGF), platelet-derived growth factor (PDGF), insulin-like growth factor (IGF), vascular endothelial growth factor (VEGF), also transforming growth factor- $\beta$ (TGF- $\beta$ ) which may modulate and prevent excessive recruitment of inflammatory leukocytes.

The secretion of these factors starts with platelet activation immediately after the addition of calcium which is the cofactor necessary for the degranulation. ${ }^{23}$

VEGF is a pleiotropic factor that activates a cascade of events inducing the revascularization of injured tissues. ${ }^{24}$ These proteins are involved in tissue healing through cells chemotaxis, proliferation and differentiation, angiogenesis and deposition of new extracellular matrix.

Reduced secretion of VEGF caused by the BF may explain the difficulty of reparation of intraoral soft tissues. ${ }^{13,25}$

The PRP has been shown to increase the number of BMSC to 4 times as much when administered together, thus assuming a role in potentiating the effects of BMSC. ${ }^{26,27}$ Although leukocytes have been proposed as additional carriers of cytokines and microbicide proteins, ${ }^{28}$ the addition of the leukocytes to the PRP (PRP-L) did not demonstrate a difference in the bactericidal power, while platelet-derived peptides have shown a role as activators of neutrophils. ${ }^{29}$

This property has been used to reduce the intra-operative (short therapy), to boost and eliminate the daily postoperative administration of antibiotics, and despite the dehiscence of the surgical wound, the latter phenomenon was almost constant.

\section{Piezosurgery}

"Piezosurgery Medical Device" (PMD) is an original surgical appliance which uses piezoelectric ultrasonic vibrations for cutting, successfully employed for performing different bone surgical procedures in the oral and maxillofacial field with great results in term of the related complications reductions. Its main advantages described are the scanty bleeding and bruising, the harmless effect on soft tissues and the low pressure needed to create bony cuts, so minimizing tissue trauma and, consequently, its associated morbidity. ${ }^{30,31}$

In the literature, a large case series suggested that bone resection performed by a high-power ultrasonic surgery associated with antibiotic therapy might lead to BRONJ healing. ${ }^{32}$

Laser

Laser devices are described as useful tools for different applications in the treatment of MRONJ, being able to perform the removal of necrotic bone by vaporization as well as biomodulation of both soft and hard tissues. ${ }^{33,34}$ Thanks to the affinity of the Er:YAG laser wavelength 
$(2940 \mathrm{~nm})$ to water and hydroxyapatite, laser technology allows for efficient ablation of hard tissues without the risk of thermal increase determining necrotic effects on tissues. Moreover, even if the classical optical window to perform biomodulating effect is in the range of 600$1000 \mathrm{~nm}$ of wavelength, there are some papers describing biomodulating effect also for $2940 \mathrm{~nm}$ wavelength. ${ }^{35,36}$

Er:YAG laser, thanks to the respect of tissue in terms of thermal increase and also to the biomodulating reported properties, is described as linked to a faster bone healing. ${ }^{37}$ Bone healing is a proliferative physiological process determined by several phases and different types of tissues (periosteum, endosteum, bone marrow, blood vessels) and cells (fibroblasts, chondroblasts, osteoblasts, and osteoclasts)..$^{38}$

The main effects of laser application in low-level laser therapy (LLLT) protocols on bone tissues seem to be related to the increase of bone nodule formation, blood vessels, alkaline-phosphatase (ALP) activity and osteoblastic activity, DNA synthesis, and of osteoblasts differentiation. ${ }^{39-43}$

LLLT stimulates cells proliferation by the induction of cell-cycle regulatory proteins and its capacity of favoring the "in vitro" differentiation of satellite cells was demonstrated. Particularly, the induction of the mytogenactivated protein kinase/extracellular signal-regulated protein kinase (MAPK-ERK) phosphorylation was observed following LLLT irradiation. ${ }^{44}$

The mechanism involved in the laser-induced bone repair is a two-steps sequence: the first, most likely related to the osteoblasts activation for bone matrix production, the second, subsequently, for osteoblast activity decrease and for osteoclast activity stimulation with the final result to promote resorption and remodeling of bone.

LLLT seems to be more effective for the bone formation at an earlier stage instead of at a later stage, due to that in the bone healing first step, the cellular component is more important, so being more susceptible to the laser action. Moreover, because the bone matrix is the main component of the healing tissue, a great number of cells are in the bone matrix, which incorporates carbonate substituted hydroxyapatite (CHA). ${ }^{45,46}$

The association of Er:YAG laser bone ablation with Nd:YAG/diode laser bone biostimulation has been already reported as a successful treatment of BRONJ, supporting this kind of approach, minimally invasive and biostimulative. . $^{33,34,47}$

The aim of this work is to present the experience of the Odontostomatology and Maxillo-Facial Surgery Unit of the Hospital of Piacenza (Italy) with a combined approach, based on the use of laser, piezosurgery and PRP, for the treatment of MRONJ.

\section{Methods}

Patients

Out of the patients evaluated at the Odontostomatology and Maxillo-Facial Surgery Unit - Special care dentistry of the Guglielmo da Saliceto Hospital of Piacenza (Italy) and identified as positive for MRONJ on the basis of recognized criteria, ${ }^{1,2} 21$ patients, 16 women and 5 men with a mean age of 72.6 years (range 60-85 years) have been treated with a combined surgical approach, after the signature of the informed consent. Eleven patients $(52.4 \%)$ were positive for treatment with zoledronate for solid tumors (7 for breast cancer), while 10 patients (47.6\%) were positive for osteometabolic diseases (8 osteoporosis, 1 rheumatoid arthritis and 1 osteoporosis and rheumatoid arthritis) and treatment with oral BPs; the duration of treatment with BPs was variable between 5 and 164 months. Out of oncological patients, 3 have been also treated with sunitinib (Table 1).

Fifteen patients (71.4\%) presented a mandibular localization for MRONJ, 6 (28.6\%) a maxillar localization (Figure 1). Based on AAOMS staging system, 2 MRONJ (9.6\%) were classified as Stage I, 15 MRONJ (71.4\%) were classified as Stage II and 4 (19\%) as Stage III.

The extension and the features of the osteonecrosis were evaluated by clinical examination and radiographically with panoramic X-rays scan and CT scan.

To all the patients it was prescribed an antibiotic therapy with amoxicillin+clavulanate $2 \mathrm{~g} / \mathrm{d}$ and metronidazole 500 $\mathrm{mg} / \mathrm{d}$ per os (or clindamycin in case of allergy), starting the therapy 3 days before surgery and interrupting the antibiotics at least 2 weeks after surgery and with a closed surgical wound.

\section{Piezosurgery}

PMD (Mectron, Italy) was applied to remove necrotic bone specimen of MRONJ sites allowing a histological analysis to finalize the diagnostic confirmation for MRONJ (Figures 2A-2B).

The instrument was used with a microsaw of $0.55 \mathrm{~mm}$ firmly moved over the bone avoiding the use of an excessive force and with an integrated saline coolant spray to maintain a low temperature and a good vision of the surgical site.

\section{Laser Devices}

Er:YAG laser device (2940 nm - Lightwalker, Fotona, Slovenia) was used in the treated patients to perform vaporization of necrotic bone until the observation of

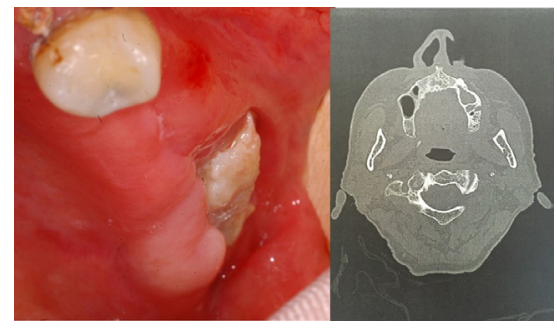

Figure 1. Stage III Left Maxillary Bone Necrosis With Sinus Involvement in a 73 Years-Old Woman Treated With Alendronate for Osteoporosis. 


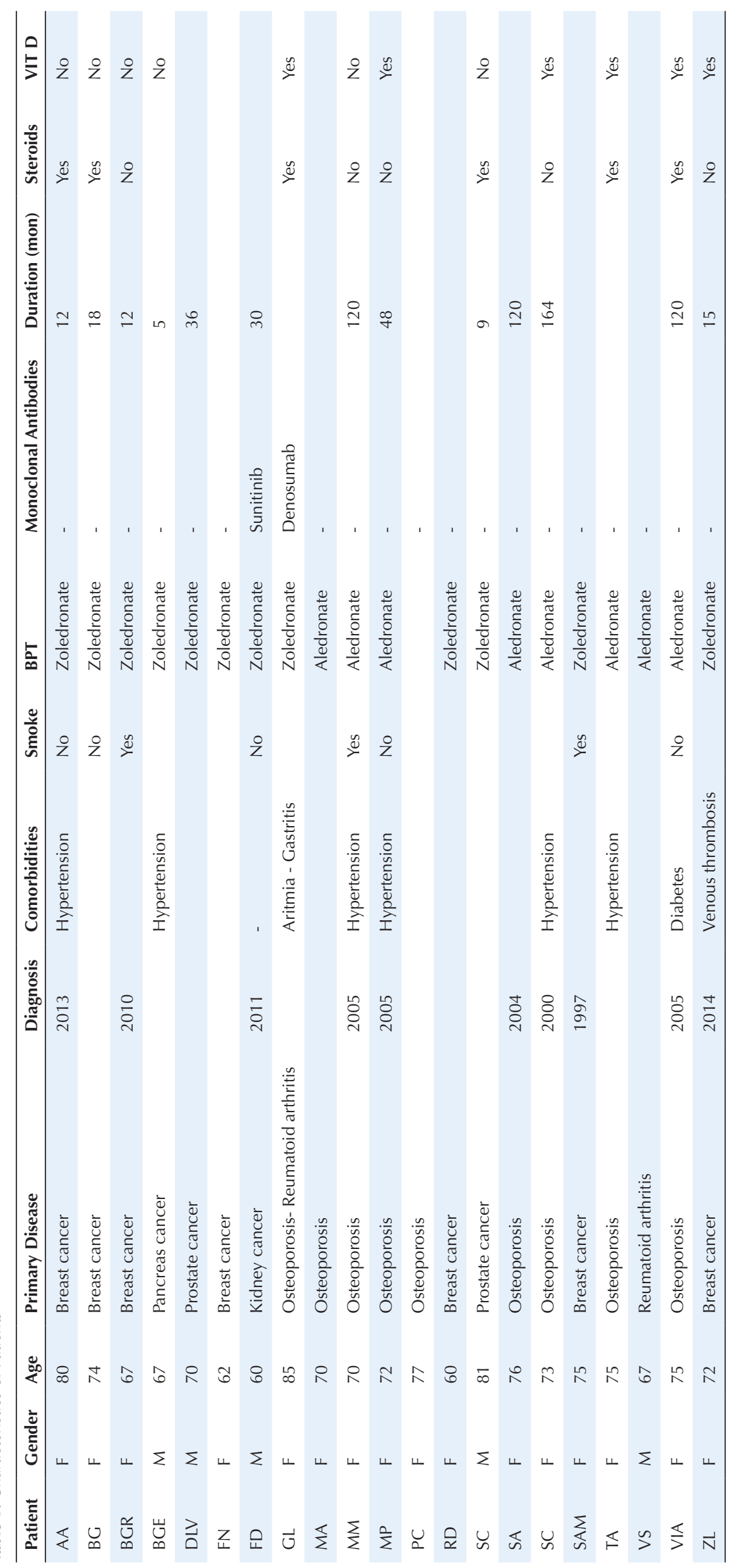


bleeding, considering that as a sign of viable, non-MRONJ affected bone (Figure 2C). Er:YAG laser was used with a mirror handpiece for non-contact application (R02) at a distance of about $0.8 \mathrm{~cm}$ corresponding to the same incidence on tissue for laser light and air-water spray with an energy of $200 \mathrm{~mJ}$ and a frequency of $20 \mathrm{~Hz}$ in Medium Short Pulse (Fluence/pulse: $39.80 \mathrm{~J} / \mathrm{cm}^{2}$ ).

Diode laser $808 \mathrm{~nm}$ is a laser useful as a surgical device on soft tissues but also for biomodulation protocols depending on the parameters. It was used to perform biomodulating effect both intraoperative and postoperatively. The first session was performed just after suturing, while the subsequent ones were 2 times/ week until suture removal on a completely closed surgical wound. Biomodulation was done with a $600 \mu \mathrm{m}$ diameter fiber in scanning mode on the surgical site with $1 \mathrm{~W}$ of power in continuous mode during 1 minute for 5 times (Theoretical fluence: $21231 \mathrm{~J} / \mathrm{cm}^{2}$ ).

\section{Platelet Rich Plasma}

Autologous platelet gel was prepared at the Department of Oncology and Hematology of the Hospital of Piacenza (Italy) during the planning of the surgery and stored until the day of the intervention. Multiple samples of whole blood were obtained from each patient and collected in 10 $\mathrm{mL}$ vacutainers. Blood was then centrifuged at $180 \mathrm{rpm}$ per 10 to separate concentrated erythrocytes from PRP and then PRP was stored at $-40^{\circ} \mathrm{C}$.

The day of the surgery, PRP was maintained at room temperature until the use and just before that thrombin and calcium gluconate were added for platelets activation and gelling process acceleration.

PRP gel was used for each patient directly on the wound, absorbed on fibrin sponge or injected with a syringe after suture directly in the wound (Figures 2D-2E).

\section{Results}

Mean follow-up was 9.6 months. All the 21 patients (100\%) experienced improvement of MRONJ with a transition to a lower stage of the Ruggero classification. Complete recovery was observed in 20 out of 21 patients (95.23\%) (Figure 2F); one patient with mandibular BRONJ in Stage 3 and treated with the combined approach, healed completely and maintained the healing for 9 months then showed a recurrence of MRONJ on the site of intervention. All patients described a good post-operative comfort, not needing painkillers and reported the absence of bleeding and a rapid healing time. The histological evaluations performed demonstrated samples of good quality and without artifacts, allowing the confirmation of the clinical diagnosis (Table 2).

\section{Discussion}

Management of MRONJ is still a challenge for oral and maxillo-facial surgeons, particularly in relation with new anti-angiogenetic drugs as denosumab and sunitinib. Guidelines are today in agreement with the use of medical approach with antibiotics in all the cases, from Stage I to Stage III, in association or not with the surgical approach. ${ }^{48}$ In our experience, as reported elsewhere in the literature, ${ }^{49}$ an early surgical approach performed in Stage I MRONJ maybe efficient for the obtaining a complete healing with a minimally invasive surgical approach.

Er:YAG laser may represent a useful option in terms of reduction of invasiveness: in fact its wavelength allows the vaporization of necrotic bone with good control of bone removal because of its affinity for water and hydroxyapatite allowing a superficial action; in addition to affinity properties, the use of a handpiece with an airwater spray limits damages the tissue avoiding temperature increase at bone level in surgical site and with this thermal necrosis. ${ }^{50}$ These aspects are related to a good comfort during and after surgery for the patient with a reduction of postsurgical morbidity (with a reduction/elimination of pain and edema) and a better and faster healing. ${ }^{51}$

Aoki et al reported that Er:YAG laser used for bone surgery even with high-level irradiation may induce cell reactions, thanks to the scattering phenomena surrounding the
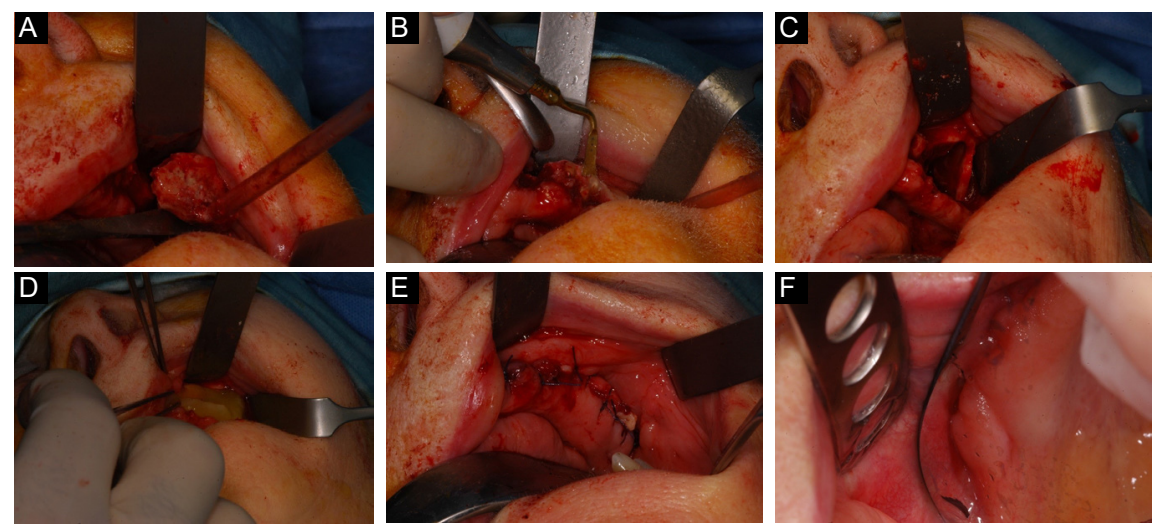

Figure 2. (A) Removal of Bone Sequestrum. (B) Osteotomy Performed With the Piezosurgical Device. (C) Bone Bleeding After Vaporization With Er:YAG Laser. (D) Placement of Gelatinous PRP. (E) Suture With PRP on Site. (F) Complete Healing at 6 Months Follow up. 


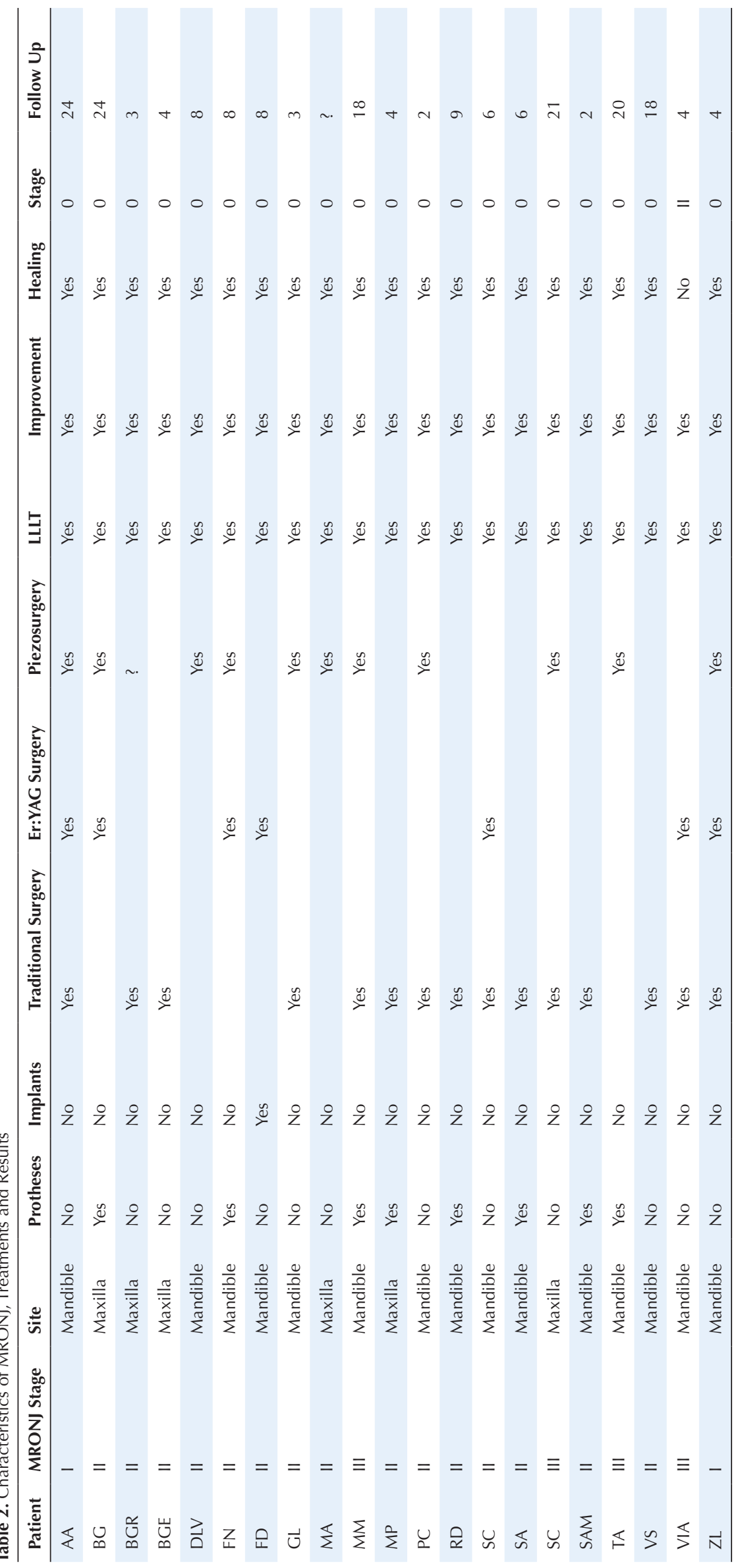


tissue irradiated, stimulating bone regeneration. ${ }^{52}$

Ninomiya et al reported a lower number of osteoclasts after pulsed laser irradiation as well as the activation of osteoblasts with increased bone formation. ${ }^{53}$

Pourzarandian et al reported a faster growth of cultures cells irradiated with an Er:YAG laser when compared with untreated groups thanks to the stimulation of gingival fibroblasts proliferation associated to an earlier mitosis and collagen fibril strands increment. ${ }^{35}$

In the combined treatment we performed on these patients, beyond the biostimulating effect of Er:YAG laser, we used a biomodulating approach with a diode laser $(808 \mathrm{~nm})$ : this kind of approach, completely safe and comfortable for the patient, may help tissue healing through the stimulation of keratinocytes, osteoblasts and endothelial cells. ${ }^{54}$

The basis for the use of PRP is the addition of GFs as FGF, EGF, KGF, IGF, PDGF, transforming VEGF and TGF- $\beta$ in suffering environments as bone exposed to the action of BFs and monoclonal antibodies; in this way, after the surgical ablation of necrotic bone and the decontamination of the surgical site, PRP may have the main role to induce tissue healing by cells chemotaxis, proliferation and differentiation, angiogenesis and deposition of new extracellular matrix. ${ }^{22}$

Sequential utilization of different high-technologies devices during all the steps of MRONJ treatment allows to perform a faster and less invasive surgery with a more comfortable postoperative healing process and it may represent a new and original approach for treating this severe adverse event.

\section{Conflict of Interests}

The authors state that there is no kind of conflict of interest regarding the publication of this paper.

\section{Ethical Considerations}

This is an observational study which Our Ethical Committee approval was not required. All treated patients signed an informed consent to the treatment performed.

\section{References}

1. Ruggiero SL, Dodson TB, Fantasia J, et al. American Association of Oral and Maxillofacial Surgeons position paper on medication-related osteonecrosis of the jaw-2014 update. J Oral Maxillofac Surg. 2014;72(10):19381956. doi:10.1016/j.joms.2014.04.031

2. Bedogni A, Fedele S, Bedogni G, et al. Staging of osteonecrosis of the jaw requires computed tomography for accurate definition of the extent of bony disease. $\mathrm{Br} J$ Oral Maxillofac Surg. 2014;52(7):603-608. doi:10.1016/j. bjoms.2014.04.009

3. Marx RE, Cillo JE, Jr., Ulloa JJ. Oral bisphosphonateinduced osteonecrosis: risk factors, prediction of risk using serum CTX testing, prevention, and treatment. J Oral Maxillofac Surg. 2007;65(12):2397-2410. doi:10.1016/j. joms.2007.08.003
4. Fusco V, Santini D, Armento G, Tonini G, Campisi G. Osteonecrosis of jaw beyond antiresorptive (bone-targeted) agents: new horizons in oncology. Expert Opin Drug Saf. 2016;15(7):925-935. doi:10.1080/14740338.2016.1177021

5. Williams WB, O'Ryan F. Management of MedicationRelated Osteonecrosis of the Jaw. Oral Maxillofac Surg Clin North Am. 2015;27(4):517-525. doi:10.1016/j. coms.2015.06.007

6. Spanou A, Lyritis GP, Chronopoulos E, Tournis S. Management of bisphosphonate-related osteonecrosis of the jaw: a literature review. Oral Dis. 2015;21(8):927-936. doi:10.1111/odi.12333

7. Ribeiro NR, Silva Lde F, Santana DM, Nogueira RL. Bisphosphonate-Related Osteonecrosis of the Jaw After Tooth Extraction. J Craniofac Surg. 2015;26(7):e606-608. doi:10.1097/scs.0000000000002051

8. Gamsjaeger S, Hofstetter B, Zwettler E, et al. Effects of 3 years treatment with once-yearly zoledronic acid on the kinetics of bone matrix maturation in osteoporotic patients. Osteoporos Int. 2013;24(1):339-347. doi:10.1007/ s00198-012-2202-8

9. Ramaglia L, Guida A, Iorio-Siciliano V, Cuozzo A, Blasi A, Sculean A. Stage-specific therapeutic strategies of medication-related osteonecrosis of the jaws: a systematic review and meta-analysis of the drug suspension protocol. Clin Oral Investig. 2018;22(2):597-615. doi:10.1007/s00784017-2325-6

10. MontebugnoliL, FelicettiL, GissiDB, Pizzigallo A, Pelliccioni GA, Marchetti C. Biphosphonate-associated osteonecrosis can be controlled by nonsurgical management. Oral Surg Oral Med Oral Pathol Oral Radiol Endod. 2007;104(4):473477. doi:10.1016/j.tripleo.2007.01.008

11. Bradaschia-Correa V, Barrence FA, Ferreira LB, Massa LF, Arana-Chavez VE. Effect of alendronate on endochondral ossification in mandibular condyles of growing rats. Eur J Histochem. 2012;56(2):e24. doi:10.4081/ejh.2012.24

12. Marx RE, Tursun R. Suppurative osteomyelitis, bisphosphonate induced osteonecrosis, osteoradionecrosis: a blinded histopathologic comparison and its implications for the mechanism of each disease. Int J Oral Maxillofac Surg. 2012;41(3):283-289. doi:10.1016/j.ijom.2011.12.016

13. Zafar S, Coates DE, Cullinan MP, Drummond BK, Milne T, Seymour GJ. Zoledronic acid and geranylgeraniol regulate cellular behaviour and angiogenic gene expression in human gingival fibroblasts. J Oral Pathol Med. 2014;43(9):711-721. doi:10.1111/jop.12181

14. Rose K, Finger IE, Ferenz KB. Interaction of clodronate with fibroblast growth factor 2 reduces FGF2-activity in endothelial cells. Biomed Pharmacother. 2011;65(1):46-51. doi:10.1016/j.biopha.2010.10.002

15. Twiss IM, de Water R, den Hartigh J, et al. Cytotoxic effects of pamidronate on monolayers of human intestinal epithelial (Caco-2) cells and its epithelial transport. $J$ Pharm Sci. 1994;83(5):699-703.

16. EngroffSL, Kim DD. Treating bisphosphonate osteonecrosis of the jaws: is there a role for resection and vascularized reconstruction? J Oral Maxillofac Surg. 2007;65(11):23742385. doi:10.1016/j.joms.2006.07.012

17. Cella L, Oppici A, Arbasi M, et al. Autologous bone marrow stem cell intralesional transplantation repairing bisphosphonate related osteonecrosis of the jaw. Head Face 
Med. 2011;7:16. doi:10.1186/1746-160x-7-16

18. Odorico JS, Kaufman DS, Thomson JA. Multilineage differentiation from human embryonic stem cell lines. Stem Cells. 2001;19(3):193-204. doi:10.1634/stemcells.19-3-193

19. White PM, Morrison SJ, Orimoto K, Kubu CJ, Verdi JM, Anderson DJ. Neural crest stem cells undergo cell-intrinsic developmental changes in sensitivity to instructive differentiation signals. Neuron. 2001;29(1):57-71.

20. Marx RE, Carlson ER, Eichstaedt RM, Schimmele SR, Strauss JE, Georgeff KR. Platelet-rich plasma: Growth factor enhancement for bone grafts. Oral Surg Oral Med Oral Pathol Oral Radiol Endod. 1998;85(6):638-646.

21. Oyama T, Nishimoto S, Tsugawa T, Shimizu F. Efficacy of platelet-rich plasma in alveolar bone grafting. J Oral Maxillofac Surg. 2004;62(5):555-558.

22. Curi MM, Cossolin GS, Koga DH, et al. Treatment of avascular osteonecrosis of the mandible in cancer patients with a history of bisphosphonate therapy by combining bone resection and autologous platelet-rich plasma: Report of 3 cases. J Oral Maxillofac Surg. 2007;65(2):349-355. doi:10.1016/j.joms.2005.12.051

23. Harrison S, Vavken P, Kevy S, Jacobson M, Zurakowski D, Murray MM. Platelet activation by collagen provides sustained release of anabolic cytokines. Am J Sports Med. 2011;39(4):729-734. doi:10.1177/0363546511401576

24. Mayer H, Bertram H, Lindenmaier W, Korff T, Weber H, Weich H. Vascular endothelial growth factor (VEGF-A) expression in human mesenchymal stem cells: autocrine and paracrine role on osteoblastic and endothelial differentiation. J Cell Biochem. 2005;95(4):827-839. doi:10.1002/jcb.20462

25. Basso FG, Turrioni AP, Hebling J, de Souza Costa CA. Zoledronic acid decreases gene expression of vascular endothelial growth factor and basic fibroblast growth factor by human epithelial cells. Br J Oral Maxillofac Surg. 2013;51(8):971-973. doi:10.1016/j.bjoms.2013.05.010

26. Kernan NA, Bartsch G, Ash RC, et al. Analysis of 462 transplantations from unrelated donors facilitated by the National Marrow Donor Program. N Engl J Med. 1993;328(9):593-602. doi:10.1056/nejm199303043280901

27. Polchert D, Sobinsky J, Douglas G, et al. IFN-gamma activation of mesenchymal stem cells for treatment and prevention of graft versus host disease. Eur J Immunol. 2008;38(6):1745-1755. doi:10.1002/eji.200738129

28. Hampton MB, Kettle AJ, Winterbourn CC. Involvement of superoxide and myeloperoxidase in oxygen-dependent killing of Staphylococcus aureus by neutrophils. Infect Immun. 1996;64(9):3512-3517.

29. Xu Z, Yin W, Zhang Y, et al. Comparative evaluation of leukocyte- and platelet-rich plasma and pure platelet-rich plasma for cartilage regeneration. Sci Rep. 2017;7:43301. doi:10.1038/srep43301

30. Itro A, Lupo G, Carotenuto A, Filipi M, Cocozza E, Marra A. Benefits of piezoelectric surgery in oral and maxillofacial surgery. Review of literature. Minerva Stomatol. 2012;61(5):213-224.

31. Pavlikova G, Foltan R, Horka M, Hanzelka T, Borunska H, Sedy J. Piezosurgery in oral and maxillofacial surgery. Int J Oral Maxillofac Surg. 2011;40(5):451-457. doi:10.1016/j. ijom.2010.11.013

32. Blus C, Szmukler-Moncler S, Giannelli G, Denotti G,
Orru G. Use of Ultrasonic Bone Surgery (Piezosurgery) to Surgically Treat Bisphosphonate-Related Osteonecrosis of the Jaws (BRONJ). A Case Series Report with at Least 1 Year of Follow-Up. Open Dent J. 2013;7:94-101. doi:10.2174/1874210601307010094

33. Vescovi P, Merigo E, Meleti M, Manfredi M, Guidotti R, Nammour S. Bisphosphonates-related osteonecrosis of the jaws: a concise review of the literature and a report of a single-centre experience with 151 patients. J Oral Pathol Med. 2012;41(3):214-221. doi:10.1111/j.16000714.2011.01091.x

34. Vescovi P, Merigo E, Meleti $\mathrm{M}$, et al. Conservative surgical management of stage I bisphosphonate-related osteonecrosis of the jaw. Int J Dent. 2014;2014:107690. doi:10.1155/2014/107690

35. Pourzarandian A, Watanabe $\mathrm{H}$, Aoki A, et al. Histological and TEM examination of early stages of bone healing after Er:YAG laser irradiation. Photomed Laser Surg. 2004;22(4):342-350. doi:10.1089/pho.2004.22.342

36. Aleksic V, Aoki A, Iwasaki K, et al. Low-level Er:YAG laser irradiation enhances osteoblast proliferation through activation of MAPK/ERK. Lasers Med Sci. 2010;25(4):559569. doi:10.1007/s10103-010-0761-5

37. Gabric D, Blaskovic M, Gjorgijevska E, et al. Evaluation of Bone Healing After Osteotomies Prepared With Er:YAG Laser in Contact and Noncontact Modes and Piezosurgery-An Animal Study. J Oral Maxillofac Surg. 2016;74(1):1828. doi:10.1016/j.joms.2015.08.017

38. Kohli N, Ho S, Brown SJ, et al. Bone remodelling in vitro: Where are we headed?: -A review on the current understanding of physiological bone remodelling and inflammation and the strategies for testing biomaterials in vitro. Bone. 2018;110:38-46. doi:10.1016/j.bone.2018.01.015

39. Almeida-Lopes L, Rigau J, Zangaro RA, Guidugli-Neto J, Jaeger MM. Comparison of the low level laser therapy effects on cultured human gingival fibroblasts proliferation using different irradiance and same fluence. Lasers Surg Med. 2001;29(2):179-184.

40. Renno AC, de Moura FM, dos Santos NS, Tirico RP, Bossini PS, Parizotto NA. Effects of 830-nm laser, used in two doses, on biomechanical properties of osteopenic rat femora. Photomed Laser Surg. 2006;24(2):202-206. doi:10.1089/pho.2006.24.202

41. Silva Junior AN, Pinheiro AL, Oliveira MG, Weismann R, Ramalho LM, Nicolau RA. Computerized morphometric assessment of the effect of low-level laser therapy on bone repair: an experimental animal study. J Clin Laser Med Surg. 2002;20(2):83-87. doi:10.1089/104454702753768061

42. Trelles MA, Mayayo E. Bone fracture consolidates faster with low-power laser. Lasers Surg Med. 1987;7(1):36-45.

43. Dortbudak O, Haas R, Mallath-Pokorny G. Biostimulation of bone marrow cells with a diode soft laser. Clin Oral Implants Res. 2000;11(6):540-545.

44. Karu T. Is it time to consider photobiomodulation as a drug equivalent? Photomed Laser Surg. 2013;31(5):189-191. doi:10.1089/pho.2013.3510

45. Huang YY, Sharma SK, Carroll J, Hamblin MR. Biphasic dose response in low level light therapy - an update. Dose Response. 2011;9(4):602-618. doi:10.2203/doseresponse.11-009.Hamblin

46. Merigo E, Bouvet-Gerbettaz S, Boukhechba F, Rocca 
JP, Fornaini C, Rochet N. Green laser light irradiation enhances differentiation and matrix mineralization of osteogenic cells. J Photochem Photobiol B. 2016;155:130136. doi:10.1016/j.jphotobiol.2015.12.005

47. Porcaro G, Amosso E, Scarpella R, Carini F. Doxycycline fluorescence-guided Er:YAG laser ablation combined with Nd:YAG/diode laser biostimulation for treating bisphosphonate-related osteonecrosis of the jaw. Oral Surg Oral Med Oral Pathol Oral Radiol. 2015;119(1):e6-e12. doi:10.1016/j.oooo.2014.04.014

48. Rugani P, Acham S, Kirnbauer B, Truschnegg A, Obermayer-Pietsch B, Jakse N. Stage-related treatment concept of medication-related osteonecrosis of the jaw-a case series. Clin Oral Investig. 2015;19(6):1329-1338. doi:10.1007/s00784-014-1384-1

49. Vescovi P, Manfredi M, Merigo E, et al. Early surgical laser-assisted management of bisphosphonate-related osteonecrosis of the jaws (BRONJ): a retrospective analysis of 101 treated sites with long-term follow-up. Photomed Laser Surg. 2012;30(1):5-13. doi:10.1089/pho.2010.2955

50. Fornaini C, Merigo E, Vescovi P, et al. Different laser wavelengths comparison in the second-stage implant surgery: an ex vivo study. Lasers Med Sci. 2015;30(6):16311639. doi:10.1007/s10103-014-1623-3

51. Fornaini C, Cella L, Oppici A, et al. Laser and Platelet-Rich Plasma to treat Medication-Related Osteonecrosis of the Jaws (MRONJ): a case report. Laser Ther. 2017;26(3):223227. doi:10.5978/islsm.17-CR-04

52. Aoki A, Mizutani K, Schwarz F, et al. Periodontal and periimplant wound healing following laser therapy. Periodontol 2000. 2015;68(1):217-269. doi:10.1111/prd.12080

53. Ninomiya T, Hosoya A, Nakamura H, Sano K, Nishisaka T, Ozawa $\mathrm{H}$. Increase of bone volume by a nanosecond pulsed laser irradiation is caused by a decreased osteoclast number and an activated osteoblasts. Bone. 2007;40(1):140-148. doi:10.1016/j.bone.2006.07.026

54. Mergoni G, Vescovi P, Sala R, et al. The effect of laser therapy on the expression of osteocalcin and osteopontin after tooth extraction in rats treated with zoledronate and dexamethasone. Support Care Cancer. 2016;24(2):807-813. doi:10.1007/s00520-015-2847-x 